\title{
E
}

HTTP://DX.DOI.ORG/10.22256/PUBVET.V11N4.342-345

\section{Análise morfométrica da glândula parótida de cabras Saanen}

\section{Rogério Magno do Vale Barroso*1, Paula de Oliveira Braga ${ }^{2}$, Maurício Kirmse ${ }^{2}$, Gustavo Milanezi ${ }^{2}$, Raphael Ribeiro Scherer ${ }^{3}$, Paulo Oldemar Scherer ${ }^{4}$, Marcelo Abidu Figueiredo $^{4}$}

${ }^{1}$ Curso de Medicina Veterinária - Centro Universitário Cesmac-Maceió, Brasil,

${ }^{2}$ Curso de Medicina Veterinária - Escola São Francisco de Assis - Santa Teresa, Brasil

${ }^{3}$ Médico Veterinário autônomo, Brasil

${ }^{4}$ Universidade Federal Rural do Rio de Janeiro - Seropédica, Brasil

*Autor para correspondência, E-mail: vetbarroso@yahoo.com.br

RESUMO. Este trabalho teve como objetivo descrever a anatomia da glândula parótida de cabras da raça Saanen, onde foram utilizadas vinte e seis cabeças de cabras domésticas, de ambos os sexos, onde as glândulas e seus ductos foram dissecados para realização da mensuração e determinação de sua morfologia, assim como o trajeto percorrido pelo ducto. Foram encontrados valores próximos, indicando simetria bilateral da glândula parótidas nestes animais, apresentando sucinto formato de "Y". Seu ducto parte da extremidade ventral da glândula, seguindo lateralmente ao ângulo da mandíbula contornando o masseter, onde abaixo do músculo zigomático, desemboca na cavidade oral, na papila parotídea.

Palavras chave: glândulas salivares, morfometria, ruminante

\section{Morphometric analysis of parotid glands of Saanen goats}

Abstract. The objective of this study was to describe the anatomy of the parotid gland of Saanen goats, where twenty - six heads of domestic goats of both sexes were used, where the glands and their ducts were dissected for the measurement and determination of their morphology, as well as the path covered by the duct. Close values were found, indicating bilateral symmetry of the parotid gland in these animals, presenting a succinct " $Y$ " format. Its duct extends from the ventral end of the gland, following the lateral to the angle of the mandible bypassing the masseter, where below the zygomatic muscle, flows into the oral cavity in the parotid papilla.

Keywords: salivary glands, morphometry, ruminant

\section{Análisis morfométrica de la glándula parótida de cabras Saanen}

RESUMEN. Este estudio tuvo como objetivo describir la anatomía de la glándula parótida de cabras de la raça Saanen, se utilizaron veintiséis cabezas de cabras domésticas, de ambos sexos, en los que se diseccionaron las glándulas y sus conductos para realizar la medición y determinación de su morfología, así como el trayecto recorrido por el conducto. Se encontraron valores similares, lo que indica la simetría bilateral de la glándula parótida en estos animales, con un breve formato de "Y". Su conducto parte del extremo ventral de la glándula, siguiendo lateralmente el ángulo de la mandíbula, contornando el masetero, donde por debajo del músculo cigomático, desemboca en la cavidad oral, en la papila parótida.

Palabras clave: glándula salival, morfometría, rumiantes 


\section{Introdução}

A cabra foi um dos primeiros animais domesticados pelo homem, empregado como fonte produtora de alimentos. Existem relatos de sua utilização na rotina doméstica há cerca de dez mil anos, podendo ser empregada como fonte produtora de insumos alimentícios como o leite, a carne e seus derivados, e até mesmo sendo utilizado para outros fins, como no caso do couro, do esterco e sua utilização como força de tração (Ribeiro, 1997).

Dentre as diversas raças de caprinos existentes, a raça Saanen é uma das principais, sendo amplamente utilizada na caprinocultura mundial. É considerada como a raça caprina com maior produção de leite, podendo em condições ótimas ultrapassar oito litros de leite por dia (Zambom et al., 2011). Mesmo sendo uma raça leiteira, produz ótimos mestiços para corte, devido ao seu grande porte, precocidade e pela sua aptidão leiteira, nutrindo assim melhor suas crias (Ribeiro, 1997).

Para uma produção e desenvolvimento pleno destes animais, deve haver harmonia do seu sistema digestivo, para que possa extrair dos alimentos os nutrientes necessários para o seu crescimento. Tendo início na boca, o processo digestivo começa pela mastigação e ação de enzimas que são produzidas em uma parte em particular que auxilia neste procedimento, as glândulas salivares (Tandler et al., 2001).

Mesmo pequenas estas glândulas exercem funções fundamentais nos processos digestivos e de degradação dos alimentos, que além de elaborarem enzimas digestivas, atuam como fator importante para a defesa dos tecidos moles da cavidade oral, dos dentes e do trato digestivo superior (Tandler et al., 2001). São de extrema importância para a manutenção do $\mathrm{pH}$ ruminal, pois produzem secreções alcalinas que servem como tampão (König and Liebich, 2011).

Dentre as glândulas salivares destaca-se a parótida, assim chamada pela sua proximidade com o ouvido, do grego para-, "ao lado", mais otós, "ouvido" (Sisson et al., 1986). É uma glândula acinosa composta, onde sua porção secretora é constituída exclusivamente por células serosas que possuem grânulos de secreção ricos em proteínas e atividade enzimática, sendo responsável pela hidrólise de parte dos alimentos ingeridos (Junqueira and Carneiro, 2013).

Seu tecido conjuntivo, assim como outras glândulas salivares, contém muitos linfócitos e plasmócitos, este último, que secreta IgA na saliva formando um complexo secretor rico em IgA, resistentes à digestão enzimática tornando-se assim um mecanismo de defesa imunológica da cavidade oral contra patógenos (Junqueira and Carneiro, 2013).

Esta glândula é envolta por uma cobertura facial que projeta trabéculas para dentro e a divide em vários lóbulos. Os ductos coletores maiores dessas trabéculas, se unem formando um único ducto que se inicia no aspecto rostral da glândula, passando medialmente ao ângulo da mandíbula circundando a margem ventral da mandíbula, emergindo na margem rostral do músculo masseter (König and Liebich, 2011). Estes ductos, por fim desembocam em uma abertura na papila parotídea situada entre os pré-molares superiores (Dyce et al., 2004).

Este trabalho teve como objetivo, descrever a anatomia da glândula parótida de cabras da raça Saanen para um maior entendimento de sua morfofisiologia podendo contribuir com tais conhecimentos na prática cirúrgica e na caprinocultura.

\section{Material e Métodos}

Para o presente estudo, foram utilizadas vinte e seis cabeças de cabras domésticas, da raça Saanen de ambos os sexos, provenientes do Laboratório de Anatomia e Morfologia Animal da Universidade Federal Rural do Rio de Janeiro. Os animais são provenientes de abates experimentais realizados no Instituto de Zootecnia da mesma instituição. As cabeças foram previamente fixadas por imersão em solução de formaldeído a 10\%.

Após o período de fixação, as glândulas e seus ductos foram dissecados, por realização de uma incisão superficial utilizando um bisturi circundando a base da orelha e em seguida uma nova incisão no terço médio da primeira até atingir a base do ângulo da mandíbula. Rebateu-se a pele após o músculo parótido auricular a fim de revelar a glândula parótida para a posterior dissecção que foi realizada cuidadosamente com agulha 12/40 até obter a visualização da parte rostral do ducto protídeo, seguindo-o até a sua desembocadura na cavidade oral para melhor precisão de sua desembocadura e localização da papila parótide.

A mensuração da glândula foi realizada utilizando paquímetro de metal, tomando as seguintes medidas, comprimento da glândula, espessura dorsal, espessura ventral, largura dorsal e largura ventral de ambos os lados. Os resultados 
obtidos foram tabulados e submetidos à análise estatística.

Para melhor ilustração do procedimento descrito e visualização da glândula parótida, as cabeças foram fotografadas com câmera digital, revelando assim o trajeto do ducto e localização da glândula conforme a Imagem 1.

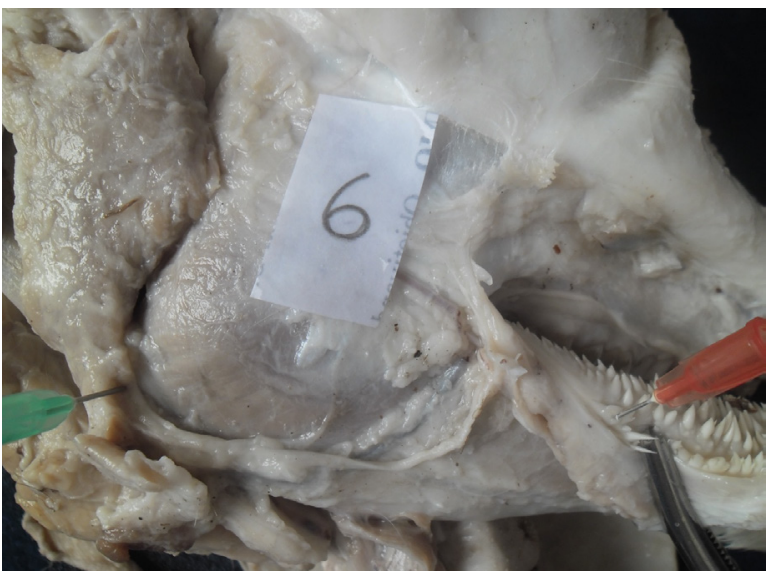

Figura 1. Imagem de cabeça de caprino da raça Saanen, evidenciando a glândula parótida e o seu ducto após dissecção (agulhas).

\section{Resultados e Discussão}

No estudo da glândula parótida, realizado nas cabras da raça Saanen, foi observado na aferição da glândula uma semelhança nas dimensões do antímero esquerdo em relação ao antímero direito, mostrando assim, existir simetria bilateral quanto às dimensões da referida glândula conforme exibido na tabela 1 .

Esta simetria bilateral da glândula parótida, foi encontrada também nos trabalhos de Fernandes Filho et al. (1988), Mendonça et al. (2004), Silva et al. (2008) em seus trabalhos realizados com cães.

Quanto à localização do ducto excretor da glândula parótida, foi constatado que este partia da extremidade ventral da glândula, junto a sua margem rostral, seguindo lateralmente ao ângulo da mandíbula contornando o músculo masseter, onde se desloca dorsalmente entre este e o músculo bucinador. Neste ponto o ducto passa abaixo dos ramos do nervo facial, juntamente com a veia e artéria facial, abaixo do músculo zigomático, para desembocar na cavidade oral, na papila parotídea.

Em relação ao seu formato, sua extremidade dorsal é larga à medida que vai se tornando delgada na direção ventral. Possui discreto formato de "Y" (Figura 1) por estar inserida próxima a cartilagem auricular, acompanhando o seu formato, conforme descrito também por Santos et al. (2011) em duas espécies de procionídeos.

Tabela 1. Relação das medidas das glândulas parótidas direitas e esquerdas de cabras da raça Saanen.

\begin{tabular}{lccccc}
\hline Glândula & Comprimento & Espessura Ventral & EspessuraDorsal & Largura Ventral & Largura Dorsal \\
\hline P. Direita & 6,38 & 0,42 & 1,242308 & 1,064 & 2,980769 \\
P. Esquerda & 6,065384615 & 0,465385 & 1,065385 & 1,157692 & 2,792308 \\
\hline
\end{tabular}

\section{Conclusão}

Foi encontrada simetria bilateral das glândulas parótidas de caprinos da raça Saanen na proporção de suas medidas e conformação. Através deste estudo, pode-se tomar novas investigações sobre a anatomia deste animal, a fim de gerar informações mais detalhadas e completas sobre a sua anatomia particular.

\section{Referências Bibliográficas}

Dyce, K. M., Wensing, C. J. G. \& Sack, W. O. 2004. Tratado de anatomia veterinária. Elsevier Brasil, São Paulo.

Fernandes Filho, A., D'Errico, A. A., Neto, J. P. \& Pereira, J. G. L. 1988. Localização topográfica da papila parotídea em cães de raça. Revista da
Faculdade de Medicina Veterinária e Zootecnia da Universidade de São Paulo, 25, 81-91.

Junqueira, L. C. \& Carneiro, J. C. 2013. Histologia Básica, 12 ed. edn. Guanabara Koogan, Rio de Janeiro.

König, H. E. \& Liebich, H.-G. 2011. Anatomia dos Animais Domésticos. Artmed Editora.

Mendonça, C. S., Carneiro, F. O., Cunha, G. N. \& Coelho, H. E. 2004. Topografia da papila parotidea em cães sem raça definida. Biotemas, 17, 217-224.

Ribeiro, S. D. A. 1997. Caprinocultura: Criação Racional de Caprinos. Nobel, São Paulo. 
Santos, A. C., Bertassoli, B. M., Oliveira, V. C., Vasconcelos, B. G., Oliveira, D. M., Leão, D. A., Carvalho, A. F., Mançanares, C. A. F. \& Assis Neto, A. C. 2011. Estrutura macro e microscópica das glândulas salivares parótidas em duas espécies de procionídeos: mão-pelada (Procyon cancrivorus, G. Cuvier, 1798) e quati (Nasua nasua, Linnaeus, 1766). Biotemas, 25, 93-101.

Silva, B. X., Pestana, F. M., Ribeiro, I. C. A. \& Figueredo, M. A. 2008. Topografia da papila parotídea em cães da raça pinscher. Arquivos de Ciências Veterinárias e Zoologia da UNIPAR, 11, 103-105.

Sisson, S., Grossman, J. D. \& Getty, R. 1986. Anatomia dos animais domésticos. Interamericana, Rio de Janeiro.

Tandler, B., Gresik, E. W., Nagato, T. \& Phillips, C. J. 2001. Secretion by striated ducts of mammalian major salivary glands: review from an ultrastructural, functional, and evolutionary perspective. The Anatomical Record, 264, 121-145.

Zambom, M. A., Alcalde, C. R., Silva, K. T., Macedo, F. A. F., Ramos, C. E. C. O., Garcia, J., Hashimoto, J. H. \& Lima, L. S. 2011. Produção e qualidade do leite de cabras alimentadas com casca do grão de soja em substituição ao milho moído. Revista Brasileira de Saúde e Produção Animal, 12, 126-139.

\section{Article History:}

Received 13 December 2016

Accepted 18 January 2017

Available on line 27 January 2017

License information: This is an open-access article distributed under the terms of the Creative Commons Attribution License 4.0, which permits unrestricted use, distribution, and reproduction in any medium, provided the original work is properly cited. 